\title{
PELATIHAN PEMBANGUNAN WEBSITE E-COMMERCE DALAM MENGELOLA HASIL KARYA SISWA/SISWI DI SMKN 5 BATAM
}

\author{
I Made Sondra Wijaya ${ }^{1)}$, Dely indah Sari' ${ }^{2)}$ \\ ${ }^{1,2}$ Teknologi Industri,Institut Teknologi Batam, Kota Batam \\ email: desondra@iteba.ac.id
}

Submit : 24/10/2021| Accept : 01/11/2021| Publish: 30/12/2021|

\begin{abstract}
MKN 5 Batam is a State Vocational High School in the city of Batam, although basically it is a public school that does not require publication for the school because it already has its own interest in students, but there is nothing wrong with always updating student activities which can later be used as information media for prospective parents of students who will prepare schools for prospective students. With the progress of information technology that is very advanced, one of which is by using the website, the needs are related to activities carried out by students at SMKN 5 Batam. The results of this activity indicate an increase in understanding in creating e-commerce websites to manage the work of students at SMKN 5 Batam. The follow-up of this training needs to be carried out with continuous training because it is not enough to only do one activity.
\end{abstract}

Keywords: Information, Technology, Website

\begin{abstract}
Abstrak
SMKN 5 Batam merupakan Sekolah Menegah Kejuruan Negeri yang ada di kota Batam, walaupun pada dasarnya adalah sekolah negeri yang tidak memerlukan publikasi terhadap sekolah karena sudah memiliki peminat sendiri siswa/siswi tetapi tidak ada salahnya untuk senantiasa update kegiatan siswa yang nantinya dapat dijadikan media informasi terhadap calon orang tua siswa/siswi yang akan mempersiapkan sekolah bagi calon siswa/siswi. Dengan kemajuan teknologi informasi yang sudah sangat maju salah satunya dengan menggunakan website maka kebutuhan terkait kegiatan yang dilakukan oleh siswa/siswi di SMKN 5 Batam. Hasil kegiatan ini menunjukkan adanya peningkatan pemahaman dalam pembuatan website e-commerce untuk mengelola hasil karya siswa/siswi di SMKN 5 Batam. Tindak lanjut dari pelatihan ini perlu dilakukan pembinaan dengan pelatihan secara berkesinambungan karena tidak cukup hanya dilakukan satu kali kegiatan saja.
\end{abstract}

Kata Kunci: Teknologi, Informasi, Website

\section{PENDAHULUAN}

Perkembangan dan kemajuan dari teknologi informasi telah banyak membantu dan mempermudah kehidupan manusia dari berbagai ragam dimensinya. Penggunaan serta penerapan teknologi informasi menyebabkan komunikasi antara masyarakat yang dibatasi oleh jarak yang sangat jauh dapat dilakukan seperti melakukan percakapan antar orang yang satu dengan yang lain dalam posisi saling berhadapan. Penggunaan teknologi informasi menyebabkan penyebaran informasi dapat dilakukan dengan sangant cepat dan dapat menjangkau sangat banyak orang (Sangkey \& Novi, 2017).

Teknologi saat ini bukan menjadi sesuatu yang langka tetapi sudah menjadi keharusan yang tidak dapat dihindari bagi kehidupan manusia. Dalam resolusi industry 4.0 sudah tidak ada lagi batasan antara kehidupan manusia dengan teknologi, segala aspek kehidupan sudah menjurus kepada apa yang dinamakan teknologi. Sebagai contoh sebelumnya pada saat akan mengunggulkan kelebihan dari suatu produk atau jasa dalam suatu media promosi maka akan dibuat brosur 
dalam jumlah banyak kemudian akan disebar luaskan, tetapi saat ini hanya dengan teknologi informasi berbasis website maka semua informasi dapat tercover, masyarakat dapat dengan mudah mendapatkan informasi tersebut dengan biaya yang tidak terlalu mahal.

SMKN 5 Batam Berdiri Pada Tanggal 12 Juni 2009 Sesuai dengan Kep. Ka.Dinas Pendidikan Kota Batam No. 345/422.4/Dikmen/VI/2009 tentang: Pembentukan Panitia Penerimaan Siswa Baru SMK Negeri 5 Batam Tahun Pelajaran 2009/2010 yang menggunakan fasilitas SMPN 27 Batam di: Kavling Seroja, Kel.Sungai Pelunggut, Kec . Sagulung Batam selama satu Semester.

Kemudian berdasarkan Keputusan Walikota Batam, Drs. Ahmad Dahlan, MH, No.KPTS. 279/HK/X/2009 tanggal 21 Oktober 2009 tentang Penetapan Nama Sekolah SD, SMP, SMA, dan SMK Negeri dilingkungan Pemerintah Kota Batam, ditetapkan berdirinya sebuah SMKN 5 Batam, di Kav. Bukit Kamboja, Kel. Sungai Pelunggut, Kec. Sagulung.

SMKN 5 Batam memiliki 10 jurusan yang dapat dipilih oleh siswa/siswi sesuai dengan standar kompetensi atau minat yang dimiliki oleh siswa/siswi.

Table 1. Jurusan yang ada di SMKN 5

\begin{tabular}{cl}
\multicolumn{2}{c}{ Batam } \\
\hline No & \multicolumn{1}{c}{ Jurusan } \\
\hline 1. & Teknik Pengelasan Kapal \\
2. & Kelistrikan Kapal \\
3. & Gambar dan Rancang Bangun \\
& Kapal \\
4. & Pemesinan Kapal \\
5. & Multimedia \\
6. & Teknik Komputer dan Jaringan \\
7. Teknik Pemesinan \\
8. Teknik Instalasi Pemanfaatan \\
9enaga Listrik \\
9. Teknik Elektronika Industri \\
10. & Produksi Grafika \\
\hline
\end{tabular}
sepuluh jurusan peminatan siswa/siswi dengan masing - masing memiliki visi, misi, kurikulum. Berikut ini merupakan website yang ada di SMKN 5 Batam sebagai media informasi bagi calon orang tua siswa/siswi dan calon siswa/siswa untuk dapat mengetahui profile dari SMKN 5 Batam.

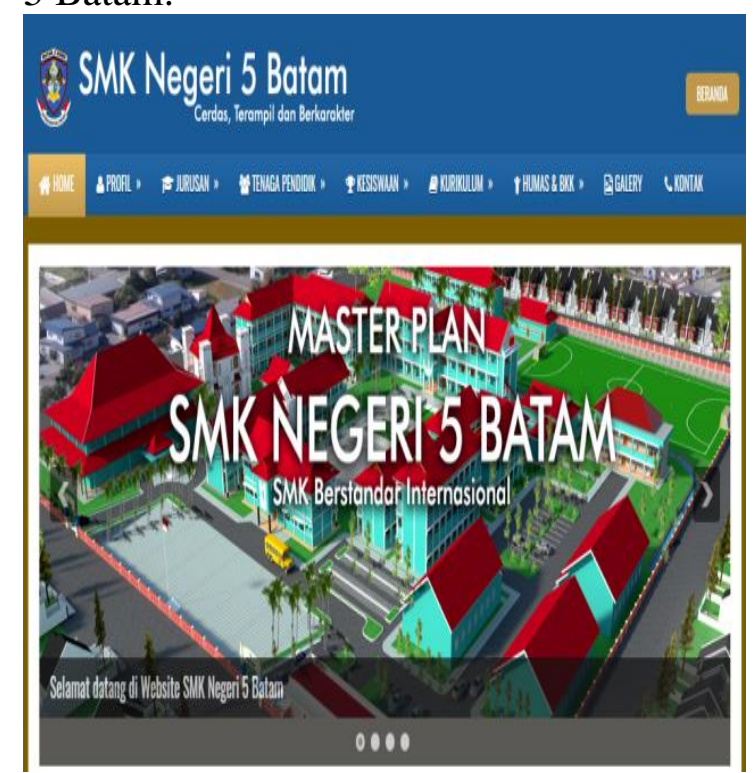

Gambar 1. Website SMKN 5 Batam

SMKN 5 Batam merupakan Sekolah Menegah Kejuruan Negeri yang ada di kota Batam, walaupun pada dasarnya adalah sekolah negeri yang tidak memerlukan publikasi terhadap sekolah karena sudah memiliki peminat sendiri siswa/siswi tetapi tidak ada salahnya untuk senantiasa update kegiatan siswa yang nantinya dapat dijadikan media informasi terhadap calon orang tua siswa/siswi yang akan mempersiapkan sekolah bagi calon siswa/siswi.

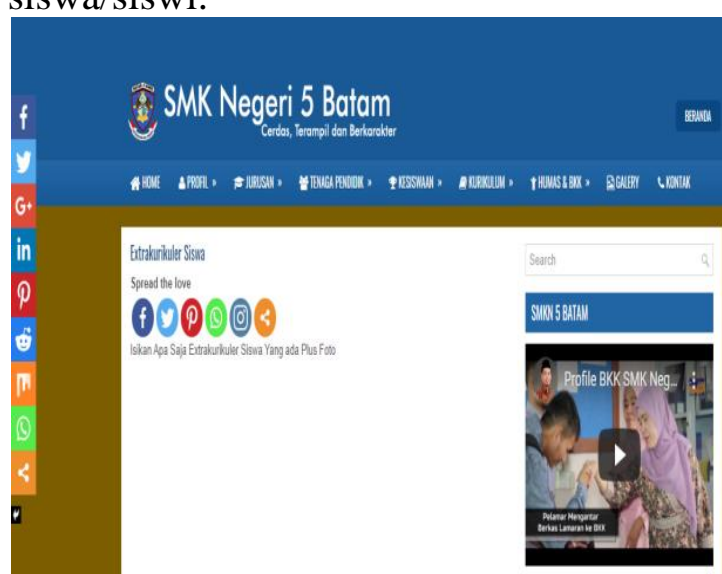

Gambar 2. Website SMKN 5 Batam

Asosiasi Dosen PkM Indonesia (ADPI) 
Berdasarkan pengamatan secara langsung SMKN 5 Batam dan website SMKN 5 Batam maka analisis permasalahan yang dapat dilakukan untuk pengabdian masyarakat ini adalah :

- Website SMKN 5 Batam bersifat statis tidak ada perubahan atau update secara simultan

- Tidak ada informasi kegiatan yang dilakukan oleh siswa/siswi pada saat melakukan kegiatan baik intern sekolah maupun extern sekolah

- Memberikan pelatihan tentang memanfaatkan social media ecommerce dalam menggunakan website dalam menampilkan karya siswa/siwi.

\section{METODE KEGIATAN}

Metode yang di terapkan dalam pengabdian masyarakat Pelatihan Pembangunan Website e-commerce Dalam Mengelola website Hasil Karya Siswa/Siswi di SMKN 5 Batam ini adalah :

\section{- Perencanaan}

a. Melakukan analisis situasi terhadap SMKN 5 Batam

b. Melakukan analisis kebutuhan terhadap website yang akan dibangun

c. Melakukan wawancara terhadap kepala sekolah, guru program studi dan guru yang mengampu mata pelajaran

d. merencanakan randon pelatihan website agar dapat difahami oleh tenaga pegajar atau guru yang mengikuti pelatihan ini

e. membagi materi menjadi modul-modul

f. download tools yang akan dijadikan sarana pelatihan website Hasil Karya Siswa/Siswi di SMKN 5 Batam

\section{- Pelaksanaan}

a. Praktek installer tools yang dibutuhkan

b. Mempraktekan modul-modul yang sudah disusun dengan sistematis

c. Melakukan uji coba/compile/debug web yang sudah di bangun d. Implementasi website SMKN 5 Batam

\section{HASIL DAN PEMBAHASAN}

Evaluasi kegiatan Pengabdian masyarakat "Pelatihan Pembangunan Website e-commerce Dalam Mengelola Hasil Karya Siswa/Siswi di SMKN 5 Batam" menjadi penting adanya sebagai bahan reviewer apakah target outcomesnya tercapai atau tidak. Berikut ini adalah evaluasi yang dilakukan :

- Persamaan pemahaman terhadap Website e-commerce Dalam Mengelola Hasil Karya Siswa/Siswi di SMKN 5 Batam

- Peranan bapak kepala sekolah, staf pengajar, dan siswa/siswi sangat berberan aktif dalam proses pelatihan Pembangunan Website e-commerce Dalam Mengelola Hasil Karya Siswa/Siswi di SMKN 5 Batam

- Peningkatan pemahaman Pembangunan Website e-commerce Dalam Mengelola Hasil Karya Siswa/Siswi di SMKN 5 Batam dilakukan dengan praktek yang dilakukan di laboratorium komputer SMKN 5 Batam, selama proses praktek tersebut dilakukan dengan dua seasion yaitu pelatihan teori dan tanya jawab yang dilakukan oleh peserta pelatihan

Tindak lanjut dari pelatihan ini perlu dilakukan pembinaan dengan pelatihan secara berkesinambungan karena tidak cukup hanya dilakukan satu kali kegiatan saja agar dapat lebih memahami sehingga apabila dikembangkan dapat seorang entrepreneur Dalam Mengelola Hasil Karya Siswa/Siswi di SMKN 5 Batam".

Selain itu, praktek setelah pelatihan juga merupakan faktor kunci dalam meningkatkan keterampilan siswa. Siswa diharapkan dapat melatih keterampilan mereka dalam membuatn dan mengelola website e-commerce walaupun pelatihan ini telah berakhir. Selanjutnya, perlu 


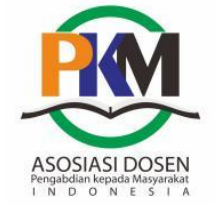

adanya pendampingan dalam praktek tersebut.

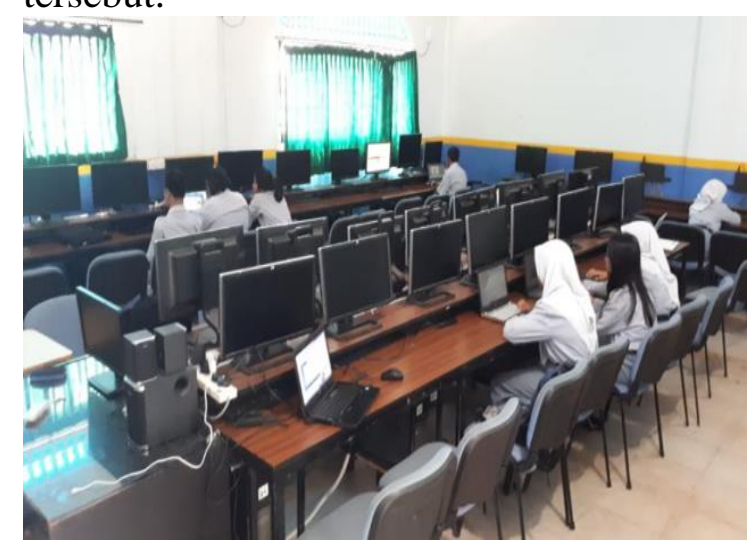

Gambar 3. Lab Komputer tempat Pelatihan Pembangunan Website e-commerce Dalam Mengelola Hasil Karya Siswa/Siswi di SMKN 5 Batam.

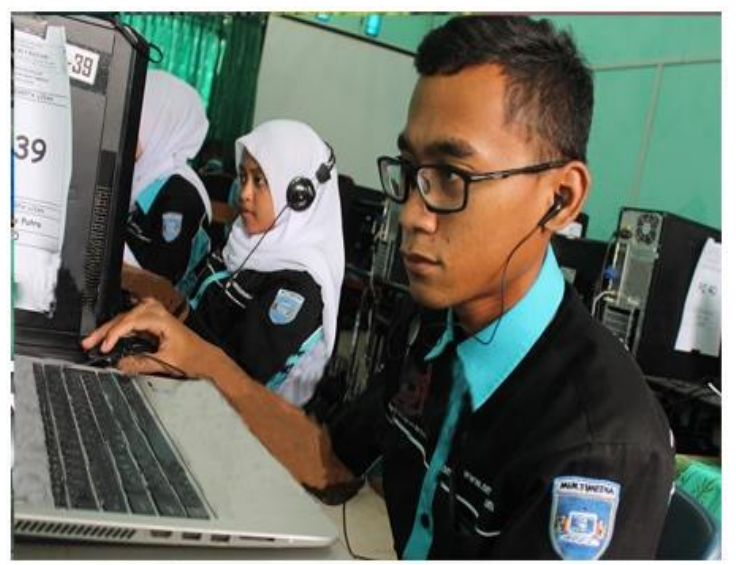

Gambar 4. Siswa siswi melakukan

"Pelatihan Pembangunan Website ecommerce Dalam Mengelola Hasil Karya Siswa/Siswi di SMKN 5 Batam"

\section{SIMPULAN}

Adapun yang menjadi kesimpulan dari pkm ini adalah :

1. Pelatihan dilakukan di jurusan Teknik Komputer dan Jaringan dengan segmentasi jurusan teknik komputer mempelajari software dan hardware

2. terjadinya perubahan terhadap pengetahuan tentang website sehingga terjadi perubahan website SMKN 5 Batam statis ke website dinamis SMKN 5 Batam

3. Media informasi tentang SMKN 5 Batam meningkat sehingga memudahkan calon orang tua dan
Jurmas Sains dan Teknologi eISSN: 2775-7013

Vol. 2 No. 4

Hal: $39-43$

Doi: https://doi.org/10.47841/saintek.v2i4.75

siswa/siswi untuk mendapatkan informasi.

\section{UCAPAN TERIMAKASIH}

Ucapan terimakasih ini ditujukan kepada bapak kepala sekolah SMKN 5 Batam dan beserta jajarannya yang sudah memberikan kesempatan kepada pengabdi untuk mengimplementasikan ilmu terkait website sehingga dapat memiliki mantaat terkhusus pengabdi umumnya kepada yang sudah mengikuti pelatihan ini yaitu pendidik dan siswa/siswi SMKN 5 Batam.

\section{DAFTAR PUSTAKA}

Binanto, I. Analisa Metode Classic Life Cycle ( Waterfall ) Untuk Pengembangan Perangkat Lunak Multimedia, J. Univ. Sanata Dharma Yogyakarta, no. MAY 2014, pp. 1-6, 2014.

Mailasari, M. Sistem Informasi Perpustakaan Menggunakan Metode Waterfall, J. Sisfokom (Sistem Inf. dan Komputer), vol. 8, no. 2, pp. 207214, Aug. 2019, doi: 10.32736/sisfokom.v8i2.657.

Purnia, D. S. Rifai, A.and Rahmatullah, S. Penerapan Metode Waterfall dalam Perancangan Sistem Informasi Aplikasi Bantuan Sosial Berbasis Android, Semin. Nas. Sains dan Teknol. 2019, pp. 1-7, 2019.

Utomo, T. P. internet adalah keamanan data. Dimana informasi di internet sifatnya adalah terbuka, dengan kemungkinan akses oleh, Steganigrafi Gambar Dengan Metod. Least Signif. Bit Untuk Prot. Komun. Pada Media Online, p. 4, 2019.

Sengkey, R., \& Novi, M. T. 2017. IbM Pemanfaatan E-Commerce Dalam Memasarkan Hasil-Hasil Pertanian. Jurnal Teknik Elektro dan Komputer, 6(3), 11-115. 
Santoso, C. B Analisis dan Perancangan Sistem Informasi Produksi, Teknois J. Ilm. Teknol. Inf. dan Sains, vol. 6, no. 2, pp. 73-83, Aug. 2019, doi: 10.36350/jbs.v6i2.42.

Susanto, R. and Andriana, A. D Perbandingan Model Waterfall Dan Prototyping, Maj. Ilm. UNIKOM, vol. 14, no. 1, pp. 41-46, 2016.

Wahid, A. A Analisis Metode Waterfall Untuk Pengembangan Sistem Informasi, J. Ilmu-ilmu Inform. dan Manaj. STMIK, no. November, pp. 1-5, 2020. 